Article

\title{
A Multi-Dimensional Hybrid Learning Environment for Business Education: A Knowledge Dynamics Perspective
}

\author{
Ioanna Pavlidou ${ }^{1} \mathbb{D}$, Nikolina Dragicevic ${ }^{1, *}$ and Eric Tsui ${ }^{2}$ \\ 1 Department of Industrial and Systems Engineering, The Hong Kong Polytechnic University, Hung Hom, \\ Kowloon, Hong Kong, China; ioanna.pavlidou@connect.polyu.hk \\ 2 Educational Development Centre, The Hong Kong Polytechnic University, Hung Hom, Kowloon, \\ Hong Kong, China; eric.tsui@polyu.edu.hk \\ * Correspondence: nikolina.dragicevic@connect.polyu.hk
}

check for updates

Citation: Pavlidou, I.; Dragicevic, N.; Tsui, E. A Multi-Dimensional Hybrid Learning Environment for Business Education: A Knowledge Dynamics Perspective. Sustainability 2021, 13, 3889. https://doi.org/10.3390/ su13073889

\section{Academic Editors:}

Grigorios L. Kyriakopoulos and Constantin Bratianu

Received: 31 January 2021

Accepted: 23 February 2021

Published: 1 April 2021

Publisher's Note: MDPI stays neutral with regard to jurisdictional claims in published maps and institutional affiliations.

Copyright: (c) 2021 by the authors. Licensee MDPI, Basel, Switzerland. This article is an open access article distributed under the terms and conditions of the Creative Commons Attribution (CC BY) license (https:// creativecommons.org/licenses/by/ $4.0 /)$.

\begin{abstract}
The main promise of new, digitally enabled and hybrid learning environments is to enable future-ready knowledge workers by equipping them with business and digital competences. However, business education (BE) research often focuses on the problems of instructional design and individual disciplines, rather than on the challenges of developing a holistic knowledge and competences required to ensure students' long-term employability. This paper, to address this gap, approaches BE as a knowledge dynamics field that consists of rational, emotional and spiritual knowledge and proposes a related framework to serve as a guide for developing and analyzing a hybrid learning environment (HLE) that would support BE. Then, it uses the developed framework in an interview-based study to understand the students' perceptions of how the implementation of an HLE in postgraduate course stimulated knowledge dynamics for BE. The results show that the HLE stimulated different aspects of knowledge due to the diversity of modes of learning-Face-to-Face (F2F) and online, the diversification of learning sources and the internationalization of the course-level curriculum. These results pave the direction for teachers to use the knowledge framework as a compass for future implementations and evaluations of similar methods.
\end{abstract}

Keywords: hybrid learning environment; hybrid learning; blended learning; business education; knowledge dynamics; higher education; learning objectives

\section{Introduction}

Business Education (BE) nowadays has a broader relevance as it is not limited anymore to the context of business studies but is becoming essential across disciplines. The digital transformation in organizations and the advances in computational power and data storage increase productivity and influence the type of skills that are required from graduates [1]. Today's workplaces rely a lot on automation and require employees to work in crossfunctional roles by putting equal emphasis on technical and non-technical skills [2-4]. To perform efficiently in this environment, employees need to have a BE that would equip them, apart from the traditional business knowledge, with strong digital, analytical and managerial skills. At the same time, advances in sciences are rapid; according to the World Economic Forum, 50\% of domain knowledge acquired during the first year of university studies is already considered outdated [4]. Inventing ways to keep the academic curriculum up-to-date and cultivating long-lasting skills and a mindset for life-long learning becomes fundamental.

In such transformative business environments, it becomes essential that BE bridges the skills gap and prepares students to excel in ever-changing and functionally heterogenous professions that operate in a globalized world. Consequently, in recent years, teaching and learning in education have been revisited to meet such contemporary requirements through the incorporation of digital technologies and online learning [5-8]. Within these approaches, classrooms are not bound by walls but can extend to virtual environments, giving rise to 
the hybrid learning environments (HLE), i.e., the considerate symbiosis of the face-to-face (F2F) and online learning experiences [9]. Technology also provides an opportunity to make education more open, such as by sharing knowledge and learning materials that are up-to-date or more industry-oriented. As such, the use of Open Educational Resources (OER) i.e., freely available digital resources [10], is becoming more prominent.

While new technological tools emerge and technology adoption in education increases, especially with the acceleration dictated by the pandemic [5,11,12], a significant challenge becomes that research often deals with new ways of instructional design and not the learning practices and objectives within the new environments [13-16]. For example, the focus is often put on identifying the benefits and challenges of hybrid learning and proposing instructional design solutions [14,16-18]. Several studies also focus on comparing online and face-to-face (F2F) learning in regards to learning outcomes [19-22].

Moreover, most of the current studies on BE focus on a traditional course context, individual disciplines or technical skills, and not on a holistic business knowledge pedagogy which would support competences such as critical thinking, digital competences, learningto-learn competences and inspiration for growth $[3,23,24]$. A few papers, indeed, deal with the topic of development of business competences for students by also considering the requirements of the contemporary $\mathrm{BE}[2,23,25-27]$. There is a lack of studies, however, that approach an HLE for BE by taking into account knowledge as a result of learning in its "full spectrum of aspects" [23]. To be more specific, our literature review reveals that there is a lack of hybrid learning studies that would account for the development of relevant business and digital skills, while also shaping students' thinking and values for future workplaces, as a requirement of contemporary, technology-enabled BE.

In this paper, drawing from the domain of knowledge management and the theory of knowledge dynamics $[25,28]$, we approach $\mathrm{BE}$ as a knowledge field that consists of three interacting forms: rational, emotional and spiritual knowledge. To support the objectives of the contemporary BE, we argue that an HLE needs to stimulate knowledge dynamics based on these three forms.

The following research question arises: How can an HLE enable knowledge dynamics that would support BE in higher education?

To address this research question, the objectives of this paper are:

- to propose a framework with knowledge forms and their components to serve as a guide for developing and analyzing an HLE for BE;

- $\quad$ to use the developed framework to understand the students' perceptions on how the proposed implementation of an HLE in postgraduate course stimulated knowledge dynamics for BE.

We have carried out the research using a qualitative study in which we first develop a knowledge-based framework by following the work of Bratianu and others on knowledge dynamics [28-30]. Then, we conduct semi-structured interviews with students to explore their views on how their HLE experience stimulated different forms of knowledge dynamics. The HLE that was a subject of the inquiry was developed by us researchers for a Knowledge Management (KM) postgraduate course at (Replace After Review) University (Replace After Review).

The analysis of the interview data shows that the implementation of HLE stimulated different aspects of rational, emotional and spiritual knowledge due to the diversity of modes of learning (F2F and online), the diversification of learning sources (textbooks, OER, social media, case studies and workshops), the internationalization and updating of a course-level curriculum (OER, the participation of business experts and guest academic lecturers). These results pave the direction for teachers to use the knowledge framework as a compass for future implementations and as a basis for evaluating student experiences.

The structure of the paper is as follows. First, a theoretical foundation section (Section 2) discusses business education from a knowledge perspective, introduces knowledge dynamics framework and follows with the development of a framework that is based on knowledge dynamics analytical lenses. The next section (Section 3) describes the 
research methodology by which knowledge dynamics framework is used to explore the students' experiences during the implementation of the HLE. Then, results are presented and followed by a discussion that connects with past literature findings (Section 4). Following Section 4, the limitations of this study and the implications for practice and future research are discussed (Section 5). The paper concludes with a summary of contributions (Section 6).

\section{Theoretical Foundations}

\subsection{Business Education, Hybrid Learning and Knowledge}

Universities are knowledge-intensive organizations which strive to take part in developing knowledge workers [31-33]. Understanding knowledge dynamics is hence essential in considering the role of knowledge as a driving force in BE. Traditional educational approaches in which teachers transfer knowledge to students are, however, not anymore sufficient to meet demands put in front of knowledge workers. This is particularly the case in the new learning environments, such as HLE. HLE combines traditional F2F learning with online (web-based) learning. Apart from traditional lectures and knowledge embedded in textbooks, it also consists of online lectures and tools, digital teaching materials such as open educational resources (OER) and platforms for knowledge sharing [34]. Breaking the classroom boundaries allows for a knowledge diversity through a broader students' participation, such as disengaged university students, individuals that have big distance from the institution and guest lecturers [35-37].

Teaching and learning in HLE should therefore account for the whole knowledge range, apart from syllabus knowledge, among others, for the development of digital competences such as learning in networks, learning from diversified media sources and leveraging on technologies [38-41]. Moreover, getting students ready for a knowledgebased economy requires an educational environment that would support the development of generic skills or generic conceptual skills in BE [23]. Generic skills are core competences that are transferrable across contexts and enable personal and professional development, such as creativity and learning-to-learn competence [24]. Further, increasing globalization requires students to be able to collaborate across borders and to develop a global mindset or global attributes [2]. This necessitates the internationalization of the curriculum. An additional mission, not exclusively related to the mode of delivery, is that BE should inspire higher values in students as well as a broader perspective about the world [42]. Great entrepreneurs have pointed out the significance of the spiritual side of the business. For example, Steve Jobs used to say that Apple's competitors' products "have no spirit in them". Stimulating a spiritual aspect of knowledge is of crucial importance. As Ji Qi mentions in his book, inspired by Laozi, "Knowledge affects action, the metaphysical determines the physical" [43].

While past works have acknowledged the need for the development of business and digital competences in contemporary higher education, to our knowledge, there are no studies which would take an analytical approach on the knowledge dynamics of BE, in particular its hybrid mode of delivery. In this paper, hence, motivated by this gap, we take as a first research objective a challenge of creating a framework with knowledge dimensions and their components, which would serve as a guide for developing and analyzing an HLE for BE from a holistic knowledge-based perspective.

In the next sections, we introduce work on knowledge dynamics, including interactions among rational, emotional and spiritual knowledge [23], which guided our research.

\subsection{Knowledge Dynamics Theory}

Knowledge dynamics refer to changes and variations in forms of knowledge at different levels: individual, group or organizational [30]. In this paper, we follow the view of those researchers who suggest that knowledge is a dynamic and non-linear entity $[37,44]$. Such a view on knowledge stands in opposition to Newtonian linear mechanics and the conceptualization of knowledge that is metaphorically perceived as object or stocks and 
flows [45-47]. Following such rationale, Bratianu and others [28-30] proposed to use the energy metaphor of knowledge as an energy field, characterized by its continuous relational interaction and transformation. According to the authors' view, knowledge can exist in different forms that create dynamics: rational, emotional and spiritual, which can be identified on the individual, group or collective level. Since in this paper we base our understanding of knowledge dynamics on these authors' conceptualization, we will provide an overview of the different forms of knowledge and their characteristics in the following paragraph.

Rational knowledge (RK) is a result of mental work and rational thinking. It reflects the objectivity of the physical environment and is expressed by using a natural or symbolic language. Since it is considered to be objective and articulable, it is explicit [48]. Emotional knowledge (EK) is a result of processing information generated by feelings and emotions in response to all external forces. It reflects the subjectivity of our body interaction with the external world and is expressed by body language and face expressivity. Spiritual knowledge (SK) is a result of spirituality, existential values and vision for the future. It reflects our understanding of the meaning of our existence and is expressed by values and beliefs. Since both subjective and inarticulable, emotional and spiritual knowledge are tacit [48].

When including the whole spectrum of RK, EK and SK forms, a more comprehensive perspective on the role of knowledge in BE emerges. In this line, we illustrate different forms of knowledge in HLE (Figure 1).

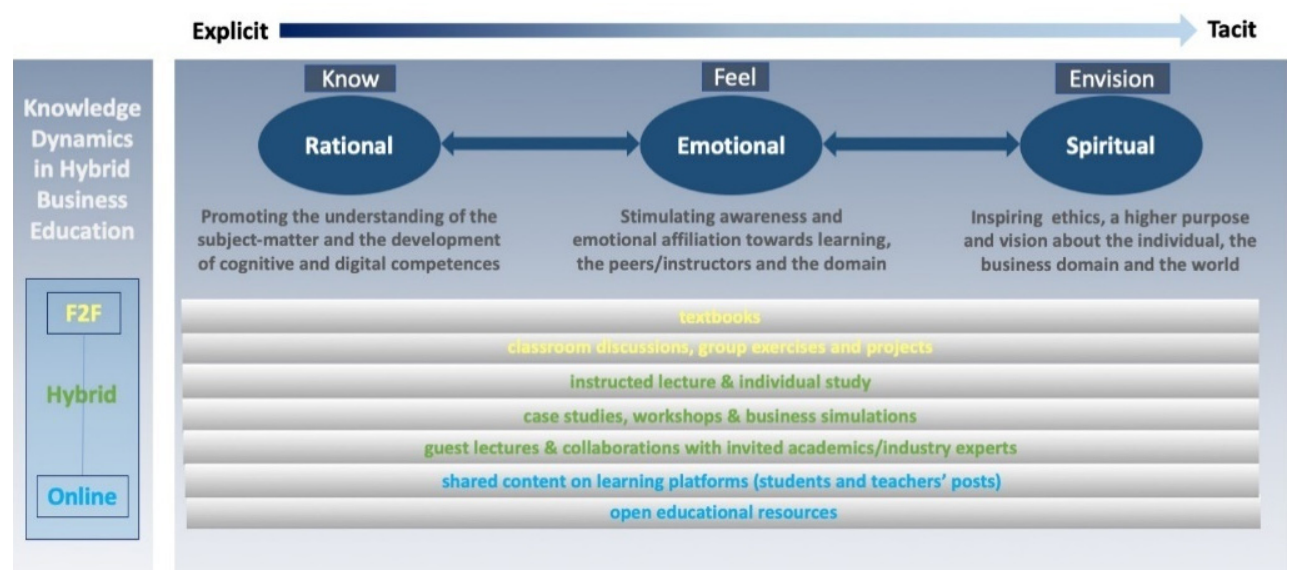

Figure 1. Hybrid Business Education and Knowledge Dynamics.

\subsection{Knowledge Dynamics Forms and Their Components in BE: A Framework}

To derive a framework with different components of knowledge forms which would serve us as a guide for developing and analyzing an HLE for BE, we draw on Bratianu and others $[23,30]$. Work on emotional ecology done by Zembylas [49] helped us to shed more light on the components of emotional knowledge.

In these works, knowledge is represented at multiple levels for a given context. For example, Bratianu and Bejinaru [30] suggest the variety of individual, group or organizational levels (compare with Zembylas [49] who uses individual, relational and socio-political levels). In this paper, we use the individual, group and collective level. Individual refers to the student, the group level oscillates between the notation of student and co-worker, and the collective refers to the business world and society. We define components for every knowledge dimension in these three levels (Table 1). 
Table 1. Knowledge components in a Hybrid Learning Environment (HLE) from a Knowledge Dynamics perspective.

\begin{tabular}{|c|c|c|c|}
\hline Forms of Knowledge/Level & Rational Knowledge & Emotional Knowledge & Spiritual Knowledge \\
\hline Individual & $\begin{array}{l}\text { Understanding the } \\
\text { subject matter } \\
\text { Acquiring digital } \\
\text { working skills }\end{array}$ & $\begin{array}{c}\text { Emotions towards the subject matter } \\
\text { The general attitude towards learning } \\
\text { Emotional awareness and } \\
\text { self-management }\end{array}$ & $\begin{array}{l}\text { Beliefs about education } \\
\text { and learning } \\
\text { Personal ethics } \\
\text { Vision about personal and } \\
\text { professional development }\end{array}$ \\
\hline Group & Collaborative learning & $\begin{array}{l}\text { Emotional affiliations with peers } \\
\text { Power dynamics }\end{array}$ & $\begin{array}{l}\text { Beliefs about groups and } \\
\text { communities } \\
\text { Group working ethics }\end{array}$ \\
\hline Collective & $\begin{array}{l}\text { Becoming aware of } \\
\text { domain applications } \\
\text { Understanding the } \\
\text { functions of corporations } \\
\text { and business world }\end{array}$ & $\begin{array}{c}\text { Emotional affiliation to a university } \\
\text { Attitude towards the } \\
\text { disciplinary professions }\end{array}$ & $\begin{array}{l}\text { Beliefs about the } \\
\text { business world } \\
\text { Beliefs about life and } \\
\text { the world }\end{array}$ \\
\hline
\end{tabular}

Rational knowledge is a result of cognition [23,30]; hence, we include components which refer to students' comprehension of subject matter, through both individual and group work. We also include components referring to the understanding of main domain applications and functions of the business world on a collective level. Apart from comprehending syllabus, during online classes, students develop their digital skills, a process that enhances students' competences for performing work in digital environments. For deriving components of emotional knowledge, we build on the concept of emotional ecology by Zembylas [49], which he defines as the "emotional knowledge in a particular social and political context, including the rich connections to emotional experiences, and relationships with others (e.g., students, colleagues, parents) over time". For example, emotional knowledge can be expressed through the way a student feels and acts about own self and the subject matter (individual level), about the peers and the instructor (group level) or academia, business world and life (collective level). This includes motivation and different psychological barriers for knowledge sharing, such as power dynamics, which can be exhibited both in F2F and online environment. Components of spiritual knowledge refer to ethics, beliefs and purpose [23,30] on all three levels: personal, group and collective. Spiritual knowledge also guides students to share knowledge with positive values and moral judgement [30], both in F2F and online environment.

When considering the above-described dimensions of knowledge dynamics, it has to be noted that knowledge is perceived as a dynamic system in which the rational, emotional, and spiritual dimensions are interconnected. Such a proposition is supported by research trends in education, psychology and neuroscience fields which show that aspects of cognition are bidirectionally influenced by aspects of emotions [50-56]. For example, problem-solving is found to be influenced by emotions [57] and motivation is linked to learning and academic performance [50,58]. While cognition and emotions affect learning and developing business competences [59], a sense of meaning and purpose is considered essential for successful business relationships and performance (spiritual knowledge) [60,61].

\section{Research Methodology}

\subsection{Research Context: HLE for BE Implemented at (Replace after Review)}

This paragraph introduces the HLE method implemented in the KM program at the Hong Kong Polytechnic University, which we will employ to address our second research objective, that is, to analyze in which way HC cultivates the knowledge dynamics. The HLE method was implemented in the academic year 2019/2020 as a part of the postgraduate KM course.

The method, described first in Dragicevic et al. [37], was developed in the quest to equip students with some of the competences necessitated by the contemporary business 
education requirements as stated in Section 2.1, such as learning in networks, learning from diversified media sources and leveraging on technologies. The approach was implemented in the context of the open pedagogy tendencies employed at PolyU characterized by the learner centricity, co-creation, hybrid learning, technology enablement, connectedness and openness of resources. Figure 2 illustrates this open pedagogy context in which students are given a more active role in creating subject knowledge, supported by technology-enabled learning environments, a network of learners, and the use of OER [62,63].

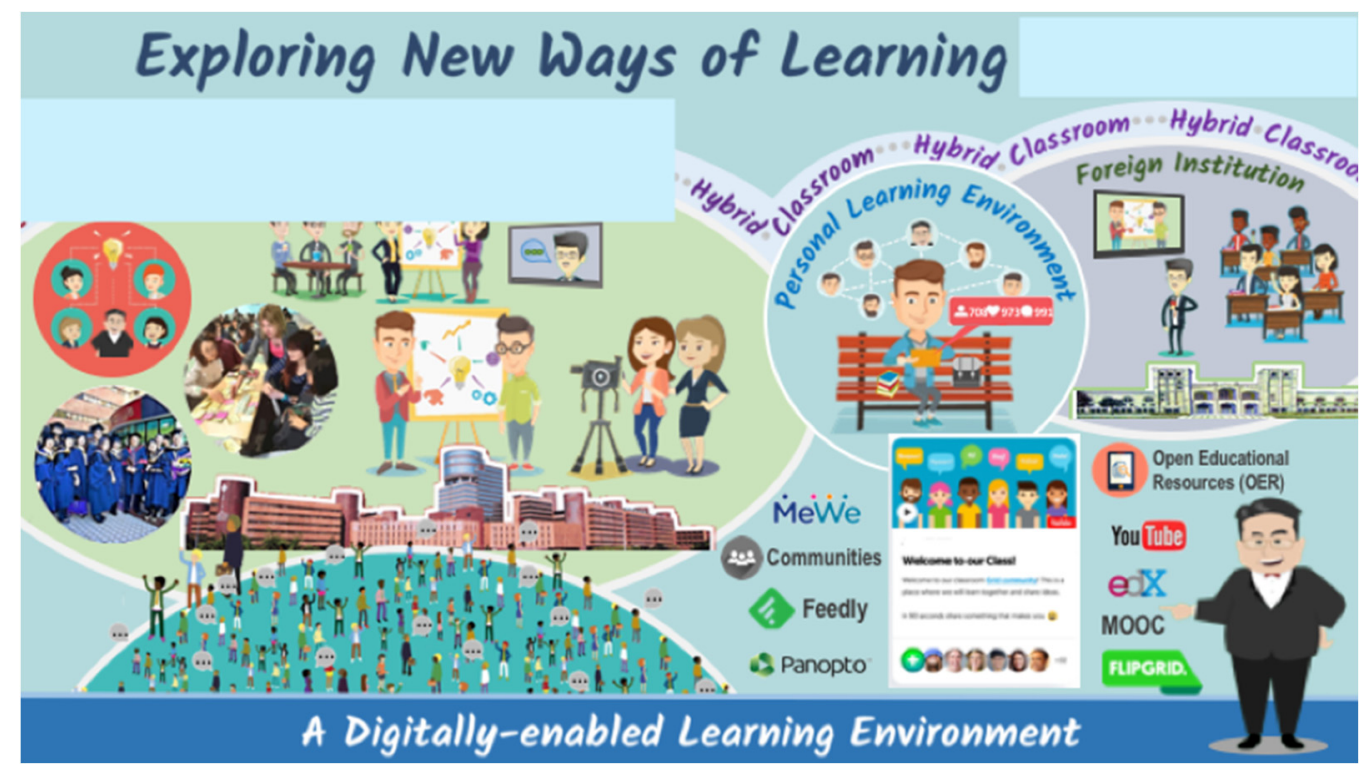

Figure 2. The poster of an adapted implementation of Hybrid Learning Environment at the (Replace After Review).

In its simplest form, a subject teacher conducts some of the classes online (typically around $30 \%$ ). The approach also utilizes more complex forms, such as a collaboration between host university and industry people or professors and students from overseas universities. For example, as illustrated in Table 2, the teacher sets up an online class where he co-lectures with the colleague from the other university or with an industry expert. In the first case, students from the other university are also invited to participate and collaborate via Blackboard collaborate (and other networking platforms, such as MeWe).

Table 2. Overview of the HLE method implemented in the Knowledge Management (KM) program.

\begin{tabular}{|c|c|c|c|c|c|c|}
\hline \multirow[b]{2}{*}{ Facilitators } & \multirow{2}{*}{$\begin{array}{c}\text { Style of } \\
\text { Interaction }\end{array}$} & \multirow{2}{*}{$\begin{array}{c}\text { Mode of } \\
\text { Interaction }\end{array}$} & \multicolumn{2}{|c|}{$\begin{array}{c}\text { Attendees and Mode of } \\
\text { Attendance }\end{array}$} & \multirow[b]{2}{*}{ Platform } & \multirow[b]{2}{*}{ Resources } \\
\hline & & & $\begin{array}{l}\text { PolyU } \\
\text { Students }\end{array}$ & $\begin{array}{l}\text { Students from } \\
\text { an Overseas } \\
\text { University }\end{array}$ & & \\
\hline $\begin{array}{l}\text { PolyU staff and } \\
\text { staff from a } \\
\text { different } \\
\text { institution or } \\
\text { industry expert }\end{array}$ & $\begin{array}{l}\text { F2F online or both } \\
\text { each facilitator } \\
\text { takes a turn to } \\
\text { present; students } \\
\text { from both sides } \\
\text { ask questions }\end{array}$ & $\begin{array}{c}\text { Both } \\
\text { synchronous } \\
\text { and } \\
\text { asynchronous }\end{array}$ & $\begin{array}{c}\text { Yes } \\
\text { F2F from the } \\
\text { classroom and } \\
\text { remotely using } \\
\text { the online } \\
\text { platform }\end{array}$ & $\begin{array}{l}\text { Yes } \\
\text { F2F from the } \\
\text { classroom and } \\
\text { remotely using } \\
\text { the online } \\
\text { platform }\end{array}$ & $\begin{array}{c}\text { Panopto, } \\
\text { Blackboard } \\
\text { Collaborate, } \\
\text { MeWe }\end{array}$ & $\begin{array}{l}\text { Textbooks, } \\
\text { OER }\end{array}$ \\
\hline
\end{tabular}

The online component of the HLE is enacted using a combination of Panopto, Blackboard Collaborate, and MeWe platforms. Both synchronous and asynchronous collaborations are used. A MeWe community platform, a screenshot of which is shown in Figure 3, is 
a particularly relevant component-here students, members of the forum, are encouraged to share relevant articles, and review, discuss and further annotate these articles.

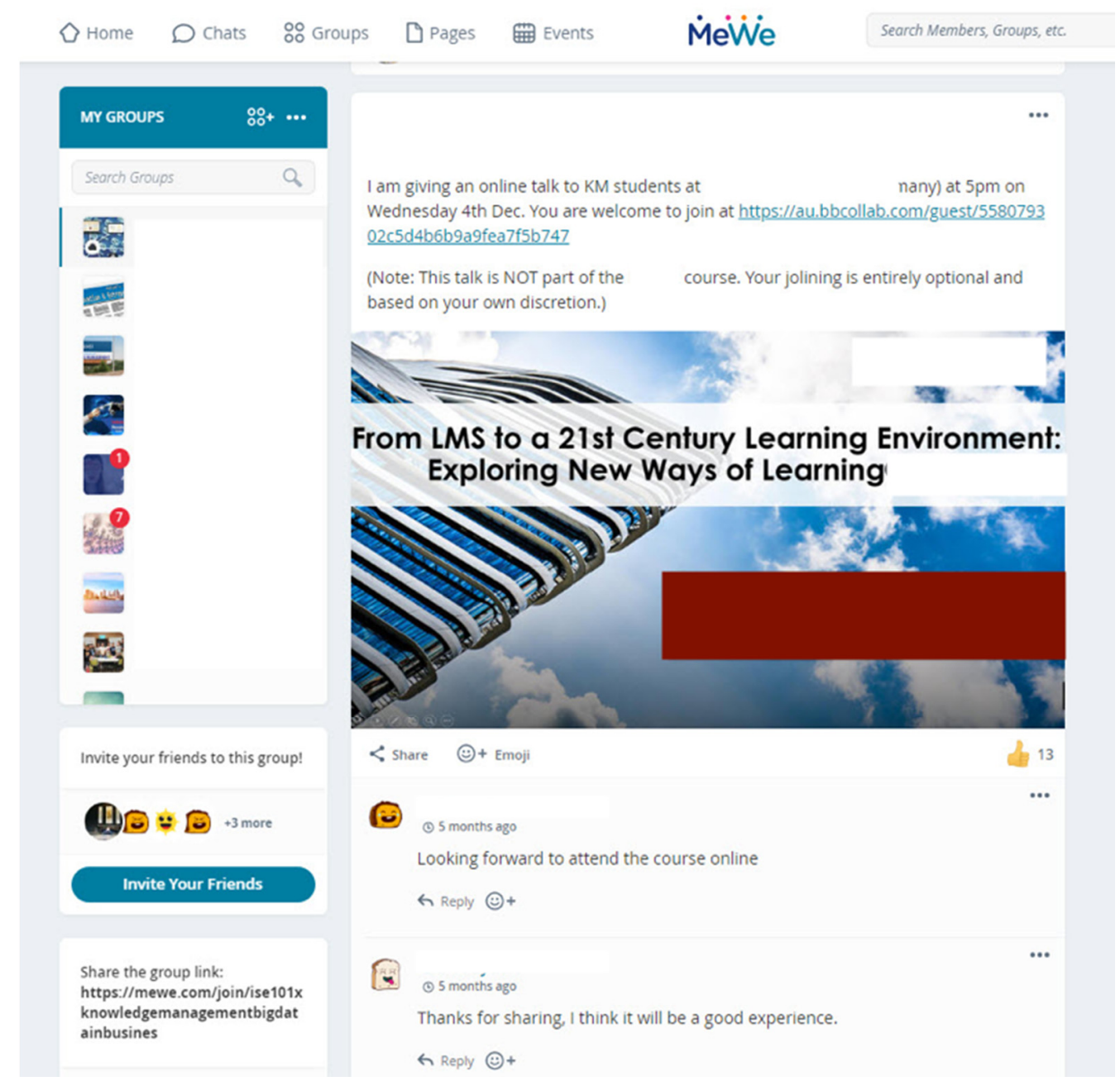

Figure 3. Using the social network of MeWe as part of the Personal Learning Environment \& Network (PLE \& N).

An important part of HLE is the use of OER, the purpose of which is to be a supplementary learning material to pre-designed course content. Students are encouraged to identify, share and use relevant and good quality OERs with their peers (with a teacher's endorsement), in the form of, among others, articles and videos posted into the chosen platforms, for example, Blackboard Collaborate or MEWE community.

\subsection{Data Collection and Sample}

To understand the students' perceptions of how the proposed implementation of HLE stimulates knowledge dynamics in the context of $\mathrm{BE}$, we have undertaken an exploratory study. Since the purpose of this research was to allow participants to "describe experiences in detail and to give their perspectives and interpretations of these experiences" [64], we have considered a qualitative research methodology as the most suitable. Specifically, the goal was to elicit students' impressions on how the components of our proposed HLE design influence their experience regarding the three forms of knowledge, rational, emotional and spiritual. The interview questions inquired students' reflection in three levels: individual, that relates to the subject matter, relational, that refers to their feelings and relationship with their peers and instructor, and the collective, that relates to their beliefs and perception about the world and the global business. 
The process of developing the interview questions was based on the Interview Protocol Refinement (IPR) framework [65] and consists of four phases. The first phase included the development of the first version of interview questions in alignment with the research questions. Since one of the objectives of this work is to use the developed framework to understand how students view their experience of Knowledge Dynamics in HLE, the interview questions were developed based on the knowledge indicators presented in Table 1 of Section 2.3. The second phase was dedicated to revising the first version of questions towards a more conversational and interactive form. In the third phase, the goal was to ensure that the questions are well understood and can provide answers to the topics of interest. For this reason, a meeting session was organized between the researchers, an academic expert from the Educational Research field and a student. This session included reading aloud the questions and commenting on possible answers. The development of the interview questions concluded with the fourth phase of testing the interview instrument. For this purpose, two pilot interviews were organized with two students. The interviews were conducted online to simulate real conditions. In each of the four phases of the IPR, the interview questions were revised and refined. The overview of the final interview questions is illustrated in Table 3.

Table 3. Overview of the interview questions.

\begin{tabular}{|c|c|c|c|}
\hline Forms of Knowledge/Level & Rational & Emotional & Spiritual \\
\hline \multirow[t]{2}{*}{ Individual } & $\begin{array}{l}\text { Does HLE help to acquire } \\
\text { understanding about the course } \\
\text { subject overall? }\end{array}$ & $\begin{array}{l}\text { Has HLE influenced your } \\
\text { mood for learning? }\end{array}$ & $\begin{array}{l}\text { Does HLE inspire you to } \\
\text { think about your-self and } \\
\text { your future? }\end{array}$ \\
\hline & $\begin{array}{l}\text { What are the advantages and } \\
\text { disadvantages of each online and } \\
\text { F2F module of the HLE in regards } \\
\text { to acquiring and understanding } \\
\text { the subject? }\end{array}$ & $\begin{array}{l}\text { Did you identify any changes } \\
\text { in the way you manage your } \\
\text { studies? How HLE influenced, } \\
\text { for example, allocating time } \\
\text { for your study, concentration, } \\
\text { prioritization of study tasks, } \\
\text { self-assessing your } \\
\text { performance, relying on } \\
\text { yourself to solve problems? }\end{array}$ & $\begin{array}{l}\text { Did it influence in any way } \\
\text { your behavior in regards to } \\
\text { the course deontology, such } \\
\text { as acting with integrity, } \\
\text { admitting mistakes? }\end{array}$ \\
\hline Group & $\begin{array}{l}\text { Do you think class discussions } \\
\text { and group exercises in HLE } \\
\text { helped you to understand the } \\
\text { subject matter? } \\
\text { How did you experience } \\
\text { collaborating with your instructor } \\
\text { and peers over the different } \\
\text { modules of HLE? }\end{array}$ & $\begin{array}{l}\text { How HLE influenced your } \\
\text { emotions about the } \\
\text { relationship with your } \\
\text { instructor or your peers, for } \\
\text { example, regarding how you } \\
\text { communicate with others, } \\
\text { your confidence, managing } \\
\text { disagreements, socializing? }\end{array}$ & $\begin{array}{l}\text { Does HLE influence your } \\
\text { accountability towards } \\
\text { others (e.g., keeping } \\
\text { promises and behaving } \\
\text { fairly (with respect)? }\end{array}$ \\
\hline Collective & $\begin{array}{l}\text { Does HLE help you to acquire } \\
\text { knowledge about business } \\
\text { applications of the course subject } \\
\text { and functions of } \\
\text { big organizations? }\end{array}$ & $\begin{array}{l}\text { Does HLE influence your } \\
\text { motivation for learning more } \\
\text { about the course domain and } \\
\text { business industry? }\end{array}$ & $\begin{array}{l}\text { Does HLE inspire you to } \\
\text { think/learn about life } \\
\text { matters/wisdom? }\end{array}$ \\
\hline
\end{tabular}

Although questions were formed before the interview, we have allowed the course of the interview to go in some other directions if prompted by the participants' responses [66]. Semi-structured interviews in this way enabled us to explore the research area, surface tacit knowledge and obtain insights underlying the participants' responses.

Participants were students of the knowledge management postgraduate master course. The students of the specific course comprise both international and local students as well as full-time and part-time professionals. An invitation was sent to the full body of the students $(n=74)$ to participate in the study voluntarily. This invitation was sent after the academic semester was over and the evaluation and results were finalized and announced. 
After the students expressed interest, they were again informed about the voluntary nature of the participation, that they can withdraw at any point, that their involvement is not related to any kind of academic assessment, that their identity will remain anonymous and the interview will be recorded, transcribed and analyzed for the purpose of the research project. There were eight final participants and they consisted of six male and two female students. Moreover, the age range was between 22 and 33, three were international students and five local, while four of them were full-time students and four were parttime young professionals. One researcher performed the interviews through an online platform over 2 months. The duration of each interview was 40-60 min. Finally, data were triangulated across the research team (one teacher, one doctoral student and one postdoctoral researcher).

\subsection{Data Analysis}

We have used thematic analysis for making sense of the interview data. Thematic analysis is a qualitative data analysis method suited for identifying and organizing patterns of meanings across data and providing relevant themes to make sense of collective experience $[67,68]$. We were interested in finding the commonalities that aid with answering our research question and focused both on obvious meanings and latent meanings and assumptions underlying them. Specifically, we were looking at the students' hybrid learning experiences in regards to the three knowledge dynamics dimensions, as explicated previously.

Following Braun and Clarke [67], in our analysis, we have followed these steps: (1) familiarizing ourselves with the leeway and character of students' responses to HLErelated questions; (2) generating initial codes by labelling with keywords the features of interviews we have assessed to be relevant to our research question. For example, one code from interview 1 was "more flexibility and self-assessment of knowledge"; (3) searching for themes and subthemes by clustering codes that share some feature which reflects a meaningful pattern. For example, we have connected codes such as "more flexibility and self-assessment of knowledge" and "competence of planning their time and organizing how and when to learn" to form a theme related to how HLE supports students' independence; (4) reviewing potential themes concerning the whole dataset, which includes revising and discarding some themes. For example, we have connected a theme "HLE supports students' independence and learning-to-learn competence" and "HLE supports the development of digital skills" into one theme "HLE promotes business competences and global perspectives"; (5) defining and naming themes for all the students' responses, a step in which we finalized a number of our themes and preformed an iterative process of finding the most informative and concise names for these; (6) producing the reports, a step in which we defined order and way of presenting the themes. Illustrative quotes were selected from data and proofread to support the reporting of the findings.

Our data analysis process ended with the four main themes which contained several mutually connected subthemes. It has to be noted that in our themes' discovery, we were predominantly following deductive or "top-down" way of analysis since we were motivated by our theoretical interest in the data $[67,69]$. To be specific, rather than being entirely open to all possible meanings that could arise from data, we were looking into details of aspects of knowledge dynamics in data. Therefore, our work was analystdriven and resulted in the four themes that reflect different forms of knowledge dynamics. Such relation to the literature on knowledge dynamics has sensitized us to some nuances in data [70], such as, for example, different aspects of emotional knowledge (e.g., power dynamics, motivation). Table 4 provides an overview of the main themes and the subthemes they are composed of. 
Table 4. Overview of themes and sub-themes.

\begin{tabular}{|c|c|c|}
\hline Form of Knowledge & Theme & Sub-Themes \\
\hline Rational & $\begin{array}{l}\text { Facilitating the breadthand } \\
\text { depth of knowledge }\end{array}$ & $\begin{array}{l}\text { Ability to learn more deeply in F2F, more focus and hence } \\
\text { comprehensibility } \\
\text { HLE supports diverse learning from various media sources } \\
\text { Online environments allow easy information sharing (via posts) }\end{array}$ \\
\hline Emotional & $\begin{array}{l}\text { Stimulating different aspects } \\
\text { of the emotional knowledge }\end{array}$ & $\begin{array}{l}\text { F2F provides more opportunity for relational EK and social connections } \\
\text { Less face-saving in the online environment } \\
\text { The motivation for continuous learning online }\end{array}$ \\
\hline Spiritual & Inspiring ethos and pathos & $\begin{array}{l}\text { Less accountability in the online environment } \\
\text { Participation of third-party speakers promotes self-reflection about } \\
\text { future work and inspires personal growth }\end{array}$ \\
\hline Generic skills & $\begin{array}{l}\text { Promoting digital } \\
\text { competences and } \\
\text { global perspective }\end{array}$ & $\begin{array}{l}\text { HLE support students' independence and gives them a more active role } \\
\text { in organizing learning (learning-to-learn competence) } \\
\text { HLE supports the development of digital skills } \\
\text { HLE supports networking and knowledge sharing with industry people }\end{array}$ \\
\hline
\end{tabular}

\section{Results and Discussion}

\subsection{Results}

In this section, we present the findings of the interview data analysis. We describe all the four main themes that we have identified under the subheadings. We support our reporting of the results with the exemplary quotes.

\subsubsection{Facilitating the Breadth and Depth of Knowledge}

The interviews showed that the proposed HLE stimulated different aspects of RK. We distinguish between the breadth and depth of the RK. Breadth refers to the diversity of knowledge topics and sources, while depth to the deeper quality of understanding of a specific topic. According to the respondents, the breadth of knowledge was particularly stimulated in the online component of HLE, whereas the depth of knowledge was nurtured in the F2F.

The breadth of knowledge was gained at digital platforms such as MeWe where the students were encouraged to share posts with articles and news on several topics and comment on other students' posts. Two students, for example, explained the value of an online learning environment in the following words:

"I have a different channel to learn, I don't only just sit and receive the knowledge of the lecture but in MeWe I see how students collaborate. I can see what other students are reading. ( . . ) they may enlighten me or inspire some new idea to come to my mind." (Interviewee 5)

"We shared about how we understood the subject and the related news. And this helped us to understand the course because this news or other sharing may not be in the textbooks, so and it increased our interest to learn more about the related things." (Interviewee 4)

Such sharing makes students aware of the breadth of knowledge in the field, which broadens their perspective and sparks their curiosity for learning. This experience was also confirmed by other interviewees who suggested that the MeWe platform enables easy information sharing and encourages to find out more about what the other classmates posted: 
"I think it was a nice tool to use because it was very straightforward. It's like most social media channels, such as Twitter, when you just post articles or whatever you want to write down. And also you could comment and you could like other people's posts and you could acknowledge the stuff that they post as well. (... ) It makes me motivated to read more articles about it." (Interviewee 1)

"I liked it because it allowed all of us, the entire class to share stuff that we found. So it's a sort of knowledge base, you don't have to do this research on your own. Your classmates would share something that they found which will help you to learn more. So, I enjoyed that aspect of it and the ability to collaborate with people in a different way." (Interviewee 3)

However, the students also noted some negative aspects of posting at the MeWe platform, which is mostly concerned with the varying quality of the shared content and the lack of good quality discussions around it. The findings suggest that the students do not engage enough in discussions by commenting on their peers' posts. The same respondent who perceived the positive effects of the online knowledge sharing suggested that the students should interact with each other more and not just "find articles and post them for the sake of having marks" (Interviewee 1). The other interviewee noted that students post a lot of content and that sometimes it is hard to perceive what is valuable there:

“There are so many materials in MeWe and it's quite time-consuming to read it all. It would be better to have maybe the top three or top one post highlighted, with a message that is interesting or important, which would professor share." (Interviewee 2)

Our interviews also revealed that the depth of knowledge was primarily better nurtured in F2F learning environments in a sense that students are typically more focused and there are more opportunities for asking questions and group work. In the words of one respondent,

"F2F learning and teaching gives some different feeling and especially when something is very hard to understand because the professor can use some gestures or a case study, divide us into groups. ( . . ) the F2F can make us learn more deeply." (Interviewee 7)

The other interviewee highlighted:

"It's easier to engage in the conversation in the F2F setting, even though in an online class I can also ask questions, but still the experience is better when it's F2F. And it is more likely for me to ask a question in the F2F setting instead of the online setting. ( ... ) the discussion part is better $\mathrm{F} 2 \mathrm{~F}$, maybe one question will lead to another." (Interviewee 6)

Another aspect regarding group discussions has been the lack of facilitators that can encourage classroom discussions:

"I think the discussion between peers (in the online mode) is less efficient than F2F because students just have less incentive to discuss with each other. I compared it with F2F because in the F2F classroom professor is monitoring." (Interviewee 8)

A few of the interviewees also emphasized that they found it beneficial that they could approach the subject professor after the class and ask him questions, whereas in the online environment a student would typically need to additionally arrange this time with a professor, by which time the moment of curiosity has already been lost.

Connected to both the depth and breadth of knowledge, the proposed HLE supports learning from diverse media sources, both textbooks and OER. The students generally spoke very positively, particularly about using OER. They found them valuable for being more up-to-date than textbooks and existing in multiple forms (such as pdfs, videos, webpages and pictures). A digital format also supports hyperlinks that potentially connect 
students to more content. It appears that OER is appealing to most of the participants since they are aligned with this generation's informal learning habits:

"I think that they [OER] are very useful because this generation of students is very much used to finding information online and not in the traditional textbooks. So usually when we see a textbook we don't want to read it and don't want to find information there-we would rather use online resources. So I think they (OER) are better." (Interviewee 1)

One student (Interviewee 7) had a particularly interesting observation that while textbooks are more connected to curriculum and subject-specific knowledge, OER can expand the learning perspective due to their diversity and breadth.

An interesting way the breadth of knowledge is facilitated in the online setting is related to the opportunity students have to work with different personalities. In the F2F setting, students tend to always form groups with the same ppl and work with them in group exercises, while in online groups there is frequently a different assignment, thus higher exposure to different personalities.

"Learning different types of people and personalities would be more online than F2F." (Interviewee 1)

"In the online setting, there is interaction with students we don't engage normally." (Interviewee 6)

According to Interviewee 6, the interaction with "outside-of-the-group" people is also related to the fact that in the online environment, introvert personalities that in the classroom are more reserved, become more active.

\subsubsection{Stimulating Different Aspects of the Emotional Knowledge}

The data analysis showed that both F2F and online components of the HLE supported emotional knowledge (EK), but different aspects of it and in various ways. In particular, it yielded results indicating that F2F mode provides more opportunity for relational EK and social connections, whereas online environments reduce face-saving tendencies and increase students' motivation for networking and continuous learning.

All the respondents agreed that the F2F environment creates an emotional context which enables familiarity and students' positive attitudes towards each other. Consequently, students are more willing to engage in group tasks and discussions than in the online environment. A typical statement in this sense was made by the participants who said:

"In F2F classroom, there are real humans, and then maybe based on your response to teachers or classmates or group [who are in the classroom], you wouldn't play mobile phone or wouldn't listen to the videos. So in F2F classroom, we could have more group discussions." (Interviewee 2)

"I feel like that in F2F people's personality are louder in a sense-you can tell more about them than online. ( .. ), you have a better understanding of their personality, whereas online, you know, you don't get the full picture." (Interviewee 3)

"In a physical environment, when you talk with your peers, you feel a need to start a casual conversation before you start doing course-related work. So there is a feeling of familiarity after you start some conversation such as: 'Oh, where are you from?' And only then we would start work. So we feel more comfortable. But in a virtual setting, it's different because all of us use our profiles, lots of us didn't even put our profile pictures. So it feels like you're not talking to a person. It doesn't feel like you need to start a conversation. So it feels more distant, I think (... ) I think it's much harder online because you can't see people F2F, you can't make eye contact and students are very reluctant to speak up." (Interviewee 1)

It appears from the data that the most dominant positive effect of F2F is the establishment of social connection (EK), which motivates students to focus and engage in group 
work. Some students also observed that the social environment, such as the university environment and out of class activities and gatherings, makes an important context to learning. In this sense, $\mathrm{F} 2 \mathrm{~F}$ provides more of a sense of community than the online environment. In words of one of the respondents:

"It isn't just about learning the theory from the textbook, but also about the environment from which students have some remarkable memories, make some new friends, some new brothers and sisters." (Interviewee 5)

The participants indicated that engagement during the lecture is perhaps harder to control in the online environment since students get more easily distracted by the available gadgets and online scrolling. As well, they do not feel the peer pressure to participate in in-class activities. For these reasons, as stressed by Interviewee 1, online environment at times leans more towards personal rather than social learning, even if group activities were assumed:

"I remember the instructor in my breakout room [in Blackboard, online learning platform] kept asking questions, but nobody wanted to reply, only maybe a few students. So it didn't feel like a group learning activity. It kind of felt like a one-on-one learning activity." (Interviewee 1)

Analyzing the interviewees' responses, we have also found that there are perceived positive effects of the online environment concerning EK. For example, it seems that whereas F2F facilitates a better understanding of the people, sometimes it is easier to work with classmates online because it is easier to mitigate communication issues with mismatching personalities:

"If there is a person who is maybe difficult to work with it, it might not be as apparent online. And it won't be too big of a problem, whereas in F2F, there could be a problem. Because there's a distance also. I don't mean physical distance, but a distance in communication, this sort of distance." (Interviewee 3)

Sharing in the online environment, at digital platforms such as MeWe, as well sparked in the interviewees the sense of joy and motivation to learn more, as demonstrated by some of the quotes in the previous section (Section 4.1.1).

One particularly interesting aspect that emerged from data regarding learning in the online environment was related to face-saving. We found two main themes regarding this. First, the students have indicated that it is easier for them to ask questions during a lecture since they feel less embarrassed to do so, as stressed by the following students:

"If you're in a classroom and you ask a question, everyone's looking at you. So sometimes people might get nervous in that sense. And online, you don't have that. You just ask a question. ( . . ) if you build up the courage in the first place to speak online, it's easier. It takes more courage to speak in person I feel." (Interviewee 3)

"In this [online] environment, I am more eager to ask questions ( . . ) I think it's embarrassing to raise our hands in the classroom." (Interviewee 4)

Second, our interviews also revealed that the students felt more confident to approach and interact with new people than they normally would in the F2F environment.

"The confidence when interacting with new people or strangers is enhanced, definitely." (Interviewee 4)

It is easier to get the email contact, but when in F2F class, you feel embarrassed to ask for their contact, because first of all, you need to maybe come to them and do a self-introduction and then talk a bit about it (Interviewee 2).

A particularly interesting observation was made by a student who recognized that collaboration in the online environment is a valuable skill to be learned: 
"You learn how to deal with people through online technology as well, to a certain extent. So you understand how to approach people differently, just because it's online, it's a different way of interacting. So you gain wisdom in that sense where you learn how to sort of interact in a different sort of way." (Interviewee 3)

The online environment also provides a source of continuous learning; since it is not time and space-dependent, students have more opportunities to come back to the recorded content or keep with learning with other resources and at their own pace:

"I think the online (part of) class is a good one for us because education and learning are a continuous process. We should keep doing it. It is not only about the knowledge we gain when we attend class F2F. That's not enough." (Interviewee 7)

"If you're considering a pace [of learning], that the lectures were recorded allows us to go back and clarify ( ... ) So you can follow your own pace if you need more time." (Interviewee 3)

\subsubsection{Inspiring Ethos and Pathos}

Students reported that their experience in the HLE influenced some aspects of spiritual knowledge in regards to their ethical self-expression and their attitude and perspective towards life and their future.

Regarding the ethical aspect, one reported issue is related to fairness and accountability. Some concerns were noted regarding the online component of the HLE due to lack of instructor's supervision:

"There may be a possibility in some exams that students may ask for help." (Interviewee 8)

When it comes to group projects and collaboration, it seems that each of the two settings, online and F2F, influence the ethical self-expression of students in a different way. For example, one student noted that the F2F environment enforces conformity with ethical standards because people can look at each other in the eyes:

"In the F2F setting people tend to behave themselves better." (Interviewee 7)

On the other hand, according to the same student, the online context can promote a different kind of fairness and accountability. Keeping work promises online appears easier because it is a more structured mode of communication in which all interactions need planning, while F2F interactions can be more relaxed and looser:

"It is easier to keep promise for your own [group] assignment online than F2F. It probably stems from the fact that this hybrid classroom is more defined and structured. So everything needs to be calculated very accurately. F2F gives a kind of flexibility, so you don't need to schedule everything so strictly and someone may end up doing more or less than the other." (Interviewee 7)

Another important finding is about a relational aspect of spiritual knowledge: trust. Students believe that inspiring and building trust should be an important objective of BE while they note that this is easier to achieve in the F2F setting:

"Humans actually can achieve more as groups rather than as individuals. No matter how smart you are, without a trusted party, a trusted brother or trusted sister, you cannot form a company." (Interviewee 5)

"The social part of schooling is very important. How do you build trust? ( ... ) [In online environment] we don't have any social life." (Interviewee 5)

One component of the proposed HLE-the participation of third-party speakersstimulated the students' thoughts regarding another aspect of spiritual knowledge. They reported it promotes self-reflection about future work and inspires personal growth. The interaction with third-party speakers triggered the students to think about what they would like to pursue after they finish their studies: 
"I think it will get me thinking about the future, about what I want to do because all of the speakers are in the industry that I would probably want to be in the future. So it does make me think about my future a lot more and it also makes me slightly anxious and nervous as well. Just seeing what they're doing, thinking about - all that possibly I'm also going to do in the future ... ( . . . ) So it really does make me think a lot and does inspire me as well, I like the work they do." (Interviewee 1)

Another student stated that third-party academic speakers sparked immediate action towards his studies, self-development and professional direction, while motivating them to start networking with the business world:

"It changed me because from professor [name] I learned about the MOOC environments and programming languages like Python or software testing. I also built my LinkedIn profile and joined a competition last year, about how to run an enterprise and to compete with each other on who will earn the most profit. And it also helped to expand my network and to even talk to some professors I didn't know." (Interviewee 5)

Last, students noted that speakers that are well-established in their domain act as life role-models for them:

"They are clever, love thinking and they're also very hard working and got the ambition to be successful. They are very goal-driven." (Interviewee 2)

"I try to draw what I can from people who have done well. So I would say in that context they are the inspiration for me, the way they work hard or apply what they have learnt correctly, all those, this minor stuff that adds a lot, how you can shape yourself." (Interviewee 3)

\subsubsection{Promoting Digital Competences and Global Perspective}

According to students' reports, the hybrid learning journey stimulated in them the development of digital competences and broadened their business and cultural perspective about the world. Digital competences are brought out as a result of the adjustment that is needed for the students to deal with the new. Technology-enabled learning environment:

"Besides the learning content, I also had to get used to the [online] setting at the same time." (Interviewee 1)

The development of digital competences was strongly emphasized by the students. They noted that they got familiar with not frequently used digital tools for knowledge sharing and co-creation:

"I think it [the learning environment] made my pre-existing skills more proficient." (Interviewee 3)

"All the functions look very easy to understand, but actually when you use them it's not that simple." (Interviewee 1)

Students also underlined that, although they were familiar with digital communications, leveraging them for academic purposes is still different and owning this experience will provide them with more confidence about their skillset when they enter the job market:

"During the hybrid class, I learned how to use online presentation tools or knowledge sharing platform which I can, as I was at what I've said before like I can introduce it to my company and show it to my boss." (Interviewee 8)

"I think that it would help me in my future as well because I will have used these platforms before." (Interviewee 1)

Students also noted aspects related to self-management as an important component that was stimulated by the proposed HLE. An HLE that includes diverse modes of content delivery and knowledge sharing is less structured compared to the traditional classroom. 
Students suggested that the hybrid structure requires a higher level of self-discipline and responsibility from the students for learning and fulfilling the course prerequisites. This, in turn, mobilizes them to take stronger initiative about allocating study time and identifying learning resources:

"I feel in the hybrid classroom environment students need to be much more independent, towards their study plan, towards how they plan their time and everything. So it does let students understand how things will work, the future where we go. When we join other companies, organizations, then, we will have to have our planning. We have to be independent and we have to be more proactive rather than reactive." (Interviewee 1)

Such an environment leads to shaping a more active, learning-to-learn role and promoting life-long learning:

"The education or learning is a continuous process. We should keep doing it. Not just to attend a class F2F. That's not enough." (Interviewee 7)

Additionally, resilience and adaptability were very commonly reported themes. Students were expected to adjust in terms of time, space and learning expectations. Specific to learning expectations, students found this learning environment stimulating their curiosity:

"I think what the hybrid class gave me ( ... ) is not only that inspired me, but also I think it led me to explore some new things. What I want, it made me curious about new things." (Interviewee 7)

At the same time, however, the learning plurality and looser structure have also been reported as having a negative effect by one student:

"It would sometimes be quite disorientating because I would be quite confused like: What are we going to learn today?." (Interviewee 1)

Apart from the competences, the proposed hybrid environment was found to promote a global perspective about business and the world. First, OER was reported as a source of up-to-date knowledge and a bridge to real-world applications:

"There are so many real applications instead of just theory and the applications are truly up-to-date." (Interviewee 5)

The OER as well as the participation of third-party speakers were highlighted as a multidimensional contribution that provides holistic thinking. The industry experts broaden the knowledge of the students about the practical applications of theory and the functions of the business world:

"They do not work in the academia and this helps because they bring in the perspective from the company." (Interviewee 6)

"What you get from academics and experts is that they broaden your perspective about the business world beyond your area." (Interviewee 5)

Furthermore, the academic guest lecturers provide a new perspective on the course content:

"You may have more dimension to understand how the theory exactly works." (Interviewee 5)

The value of getting the feeling of what is happening in different parts of the world was also highlighted as an important element of acquiring a global perspective:

"The course did touch a lot of bigger topics, not just specific companies or specific business process management in a company. It covered a vast amount of topics. So yeah, definitely it did expand my views about different corporations as well as the entire world in general." (Interviewee 1)

"[The course offered] different voices from different countries." (Interviewee 7) 


\subsection{Discussion}

In this work, we propose a knowledge dynamics framework to support BE in an HLE. Then, based on this framework, we conduct interviews with students to understand their perceptions on how our implementation of an HLE stimulates knowledge dynamics for BE.

Our analysis reveals that different modules of the HLE can influence different aspects of the knowledge dimensions. In this sense, each setting has its benefits and limitations leading to the potential to complement each other in creating knowledge dynamics for hybrid BE. Table 5 presents the summary from the analysis of the interview data organized by knowledge forms and each of the two modes-online and F2F.

Table 5. Summary of the results.

\begin{tabular}{|c|c|c|c|}
\hline Main Theme & Rational Knowledge & Emotional Knowledge & Spiritual Knowledge \\
\hline \multirow[t]{9}{*}{$\mathrm{F} 2 \mathrm{~F}$} & Perceived positive effects & Perceived positive effects & Perceived positive effects \\
\hline & Higher focus & Emotional ambience that enables familiarity and & Easier to build trust \\
\hline & More space for engaging & students' positive attitudes towards each other & Easier to conform with \\
\hline & in-class discussions & Enhanced socialization & general relational ethical \\
\hline & Facilitation of depth of & Easiness to perform group activities & standards \\
\hline & knowledge (textbooks, & University environment and out of class activities & \\
\hline & Development of digital skills & to learning & \\
\hline & Perceived disadvantage & Perceived disadvantage & Perceived disadvantage \\
\hline & Reservations for speaking out & Increased hesitance to approach someone & Harder to admit mistakes \\
\hline \multirow[t]{13}{*}{ Online } & Perceived positive effects & Perceived positive effects & Perceived positive effects \\
\hline & Easy information sharing & Motivation to find more information based on & More accountability in \\
\hline & Up-to-date knowledge & what peers shared & group work \\
\hline & $\begin{array}{l}\text { Facilitation of breadth of } \\
\text { knowledge due to topics and }\end{array}$ & $\begin{array}{l}\text { Motivation for continuous, life-long learningLess } \\
\text { face-saving, more confidence }\end{array}$ & $\begin{array}{l}\text { Inspiration to establish } \\
\text { connections with industry }\end{array}$ \\
\hline & resources diversity & Supports students' independence and & people \\
\hline & Enriches knowledge about & learning-to-learn competences & Broadens global business \\
\hline & business applications and & Enhances resilience and adaptability & and cultural perspective \\
\hline & Empowering learning interest & & self-reflection about future \\
\hline & $\begin{array}{l}\text { due to interactivity of } \\
\text { educational resources }\end{array}$ & & $\begin{array}{l}\text { Motivation for learning } \\
\text { and development }\end{array}$ \\
\hline & Perceived disadvantage & Perceived disadvantage & Perceived disadvantage \\
\hline & Less engaging class & Students easily distracted by the available gadgets & Harder to build trust \\
\hline & discussions & and online scrolling & Consequences from lack of \\
\hline & Varying content quality & Harder to establish deep connections with peers & instructor's supervision \\
\hline
\end{tabular}

Looking at the students' impressions on the advantages of the F2F setting, it becomes apparent that they mostly relate to the benefits provided by the students' physical proximity in the university classroom during the learning activities. As presented in the Results section, such proximity aids with building an emotional ambience that enables familiarity and rapport (EK). This ambience enables higher within-group interactions and supports socialization (EK). Previous studies have also highlighted physical presence as a key factor for more frequent peer interaction and socialization $[35,71]$. Students noted that they are able to focus better in a F2F environment (RK) due to a lack of digital distractions and because they are in the physical presence of others (instructor and classmates). Further to higher focus, proximity also enables a higher degree of spontaneity; both of which lead to increased engagement in classroom discussions (RK), confirming similar findings from past qualitative studies [71-74]. Moreover, supported by a feeling of connectedness and community, they feel it is easier to collaborate and socialize inside and outside of the classroom (EK). This feeling of community has been also illustrated in the study by Jaggars (2014) in which students in a hybrid community college program select at least a few F2F courses to enjoy peer interaction and maintain the tie to their school. The proximal and direct interactions promote also a greater sense of peer-to-peer accountability and trust 
(SK). The students explained that a high sense of accountability is a result of a tendency to conform to general ethical standards when people look each other in the eyes, i.e., a "tendency to behave better in person". This immediacy combined with the consistency of interactions with specific individuals supports the traditional feeling that trust is built in F2F interactions [75].

Our analysis, however, showed that the F2F setting can as well hinder knowledge dynamics. Some students might tend to be more reserved inside the classroom, suppress their thoughts and not initiate communication on course topics or avoid to approach new students (EK). This finding is consistent with previous studies on face-saving tendencies, power tensions and shyness exhibited by East-Asian students that result in reservations to express and fear of being wrong (Huang et al., 2011; Paulhus et al., 2002; Wang, 2014).

On the other hand, students expressed that the online components of the hybrid learning environment allowed easier knowledge sharing between peers through social networking platforms, such as MeWe (RK). Moreover, despite finding that the group work and social interactions are not facilitated optimally in the online setting, as supported by several past studies $[35,71,76]$, students pointed out some interesting positive aspects about this theme. Students noted that when working in groups online, they need to plan everything very carefully and this enforces a detailed task assignment and commitment that enhances group accountability (SK). Enhanced knowledge sharing and work progress transparency have been noted also in other studies that evaluate the use of online tools for group projects [71,77]. On the contrary, the F2F environment accommodates more laid-back interactions and requires less planning which may lead to a free-rider phenomena. Another interesting finding is that the online group work gives the students opportunities to work with different personalities since in the online setting they form groups also with classmates that don't belong to the cluster of usual friends (EK). This finding is also underlined in another study [73], but has not received much attention in the hybrid learning research. Among the interesting "social advantages" is also reported the mitigation of personality differences due to the "distance" of online communication (EK). This "distance" can serve also as a fertile ground for students that are very reserved to express themselves in the physical classroom due to face-saving tendencies (EK).

The online environment also enabled access to OER that provide more up-to-date, practical and global knowledge (RK). This result is in line with aspirations about OER to promote learning with a global character $[78,79]$. This has been enhanced by the participation of third-party speakers, that offered new dimensions thus promoted a broader understanding of the course topics (RK) but also about the global industry domain and different cultures (SK). Moreover, the lectures and interaction with well-established academics and experts has been considered also an inspirational element for the students, who identified them as life and business role-models (SK). This paves the way to fill a gap in today's BE related to the universal challenge to build a "Moral Compass" for students both in F2F setting but especially in the online mode due to the linear implementation of online learning $[42,80]$.

Last, our results show that the online components of the HLE have certain disadvantages. Students highlighted among them the varying quality of the materials shared in the collaborating platforms (RK), exhibiting an issue raised also by other studies which highlight the difficulty of students to distinguish trustworthy knowledge sources (Tambouris et al., 2014; Yang and Chen, 2008). Moreover, the lack of quality peer discussions in collaborative platforms has been also reported. This has been illustrated by several studies suggesting solutions such as using discussion facilitators or promoting suggested discussion inquires [81]. Consistent with previous studies, online environments have also proven to cause distractions that act as obstacles to students' learning and motivation (EK) (Winter et al., 2010) and posit challenge of building students' trust (SK) [82].

The proposed HLE had a positive perceived effect on the development of global perspectives and attributes and the development of digital competences. This is especially relevant now, in the COVID era, when the students are constrained to study from home. 
The online presence of industry speakers and professors from abroad aided with the "internalization of the curriculum at home" [83], whereas the use of various digital tools supports students' independent learning.

\section{Limitations and Implications for Future Research and Practice}

There are some limitations regarding the current work. This study is a single-case qualitative study serving as an initial discussion on the phenomena of knowledge dynamics in HLE. The findings of the study show a necessity for further research on knowledge practices and strategies in higher education with the purpose of supporting the development of a holistic business curriculum that would enable future-ready knowledge workers. We believe that such studies would benefit from design-based and experimental research designs which would tap into HLE learning practices in different conditions over time. Further research could also build on the results of this study and shed light on the reasons why certain learning styles adapt more effectively to different learning environments.

We also highlight some practical implications on the design and facilitation of HLEs. When attempting to enact HLEs, awareness of different forms of knowledge and their interactions is beneficial and can promote a more proactive approach. The use of knowledgesharing platforms such as MeWe can contribute to students' awareness of relevant resources and information (RK). However, it cannot resolve the issue of the content quality control, the lack of students' motivation to discuss the postings (EK), and the weaker accountability and trust exhibited in online learning environments (SK). To support the knowledge-based interactions among the students, practitioners should learn different knowledge strategies so they could be better prepared for the online sessions. Preparations could include assigning facilitators for discussions (TAs or student helpers), gamifying students' sharing and commenting, putting metadata (tags) on the contents or labelling the most valuable contributions. This would provide students with the enhanced visibility of the quality of contributions, and hence potentially with a position which would increase the sense of personal and group accountability.

Furthermore, as demonstrated in our study, different modules of HLE-F2F or online -facilitated formation and activation of knowledge forms in various ways, with both perceived positive and negative effects. Such a hybrid design potentially creates a more inclusive environment for students with different learning styles. For example, our results showed that the face tendency features typically decreases in online environments due to the sense of distance and anonymity of students. Such a finding is in line with previous studies which noted that online and F2F learning environments are differently effective for students with certain learning styles $[84,85]$. We recommend practitioners to become sensitive to individual students' learning styles and to allow them more flexibility to organize their own learning. For example, teachers could provide a variety of means by which students can ask questions, share and access relevant information and suggest ideas-both F2F and via social learning platforms such as MeWe. This and similar learning platforms particularly provide opportunities for features such as interactive polls which could be utilized when conducting classes online. As well, teachers could become more sensitive to some students' inclination towards visual and video OER resources and provide more examples with visual illustration and video explanation to these students.

\section{Conclusions}

Amid technological advances, including the ongoing development of digital learning platforms and digital educational resources, the need to revisit teaching and learning receives growing attention in higher $\mathrm{BE}$ research. HLE which combines F2F and online learning is especially becoming a popular way of delivering courses in BE and a subject of interest in academic literature. While there have been numerous studies focusing on the development of business competences, they do not specifically focus on HLE and often remain fractional in the scope of knowledge they cover. 
This paper contributes with a holistic framework containing the three forms of knowledge dynamics - rational, emotional and spiritual — and their components to analyze HLE which would support BE. We proposed that such knowledge dynamics guideline could be a valuable tool to support the development of relevant students' competences across different learning environments, as well as a tool for assessing new teaching and learning methods developed to meet the challenges of contemporary higher education.

This paper also contributes with an interview-based study which, based on the developed guideline, inquires students' perceptions of how the HLE applied it in a postgraduate course at the HK (Replace After Review) contributed to the formation of different knowledge forms. This study found that there are both positive and negative aspects of the F2F and online learning environment on the formation of three dimensions of knowledge and suggests the possible areas of improvements. It also highlighted the benefits of hybrid learning design and showed how the two modes of delivery-F2F and online-are complementary to each other and support the formation of knowledge in different ways. Overall, the study concluded how the proposed HLE stimulated the integration of all types of knowledge, i.e., the integration of emotional and spiritual knowledge with rational knowledge. Students were, to a great extent, motivated to learn and act with positive values in both F2F and online learning environments. This implies that the HLE environment stimulated students' independence and curiosity to learn, and the development of generic business competences such as learning-to-learn competence, digital competences and global perspectives which will aid with their employability and adaptability to changing and digitalized learning environments.

While our results are mostly consistent with the previous research on HLE, what they report has not so far been specifically discussed in the context of knowledge dynamics. Therefore, the main contribution of this study stems both in indicating underlying relevant components of knowledge dynamics in HLE and in providing empirical evidence of expression of different knowledge forms in relation to prior literature.

Author Contributions: The authors contributed equally to this work. All authors have read and agreed to the published version of the manuscript.

Funding: The work covered in this paper is funded by a "Exploring New Ways of Learning project at PolyU" (Project code is GYF18-19/PT1/ISE01) by The Hong Kong Polytechnic University. Support by the university is gratefully acknowledged.

Conflicts of Interest: The authors declare no conflict of interest.

\section{References}

1. Robles, M.M. Executive Perceptions of the Top 10 Soft Skills Needed in Today's Workplace. Bus. Commun. Q. 2012, 75, 453-465. [CrossRef]

2. Minocha, S.; Hristov, D.; Leahy-Harland, S. Developing a future-ready global workforce: A case study from a leading UK university. Int. J. Manag. Educ. 2018, 16, 245-255. [CrossRef]

3. Nisula, K.; Pekkola, S. How to move away from the silos of business management education? J. Educ. Bus. 2018, 93, 97-111. [CrossRef]

4. World Economic Forum. The Future of Jobs Report 2020. Available online: https://www.weforum.org/reports / the-future-ofjobs-report-2020/in-full/ (accessed on 19 November 2020).

5. Bower, M.; Lee, M.J.W.; Dalgarno, B. Collaborative learning across physical and virtual worlds: Factors supporting and constraining learners in a blended reality environment. Br. J. Educ. Technol. 2016, 48, 407-430. [CrossRef]

6. Kemp, N.; Grieve, R. Face-to-face or face-to-screen? Undergraduates' opinions and test performance in classroom vs. online learning. Front. Psychol. 2014, 5, 1278. [CrossRef] [PubMed]

7. Sullivan, T.M.; Freishtat, R. Extending Learning beyond the Classroom: Graduate Student Experiences of Online Discussions in a Hybrid Course. J. Contin. High. Educ. 2013, 61, 12-22. [CrossRef]

8. Webb, H.W.; Gill, G.; Poe, G. Teaching with the Case Method Online: Pure Versus Hybrid Approaches. Decis. Sci. J. Innov. Educ. 2005, 3, 223-250. [CrossRef]

9. Bersin, J. The Blended Learning Book: Best Practices, Proven Methodologies, and Lessons Learned; John Wiley \& Sons: Hoboken, NJ, USA, 2004.

10. D'Antoni, S. Open Educational Resources: Reviewing initiatives and issues. Open Learn. J. Open Distance e-Learn. 2009, 24, 3-10. [CrossRef] 
11. Nancy, W.; Parimala, A.; Livingston, L.M. Advanced Teaching Pedagogy as Innovative Approach in Modern Education System. Procedia Comput. Sci. 2020, 172, 382-388. [CrossRef]

12. Skulmowski, A.; Rey, G.D. COVID -19 as an accelerator for digitalization at a German university: Establishing hybrid campuses in times of crisis. Hum. Behav. Emerg. Technol. 2020, 2, 212-216. [CrossRef]

13. Liu, Q.; Geertshuis, S.; Grainger, R. Understanding academics' adoption of learning technologies: A systematic review. Comput. Educ. 2020, 151, 103857. [CrossRef]

14. Miranda, P.; Pedro, I.; Costa, C.J.; Pifano, S. Validation of an E-Learning 3.0 Critical Success Factors Framework: A Qualitative Research. J. Inf. Technol. Educ. Res. 2017, 16, 339-363. [CrossRef]

15. O'Byrne, W.I.; Pytash, K.E. Hybrid and Blended Learning. J. Adolesc. Adult Lit. 2015, 59, 137-140. [CrossRef]

16. Raes, A.; Detienne, L.; Windey, I.; Depaepe, F. A systematic literature review on synchronous hybrid learning: Gaps identified. Learn. Environ. Res. 2019, 23, 269-290. [CrossRef]

17. Cremers, P.H.M.; Wals, A.E.J.; Wesselink, R.; Mulder, M. Design principles for hybrid learning configurations at the interface between school and workplace. Learn. Environ. Res. 2016, 19, 309-334. [CrossRef]

18. Gradel, K.; Edson, A.J. Cooperative Learning: Smart Pedagogy and Tools for Online and Hybrid Courses. J. Educ. Technol. Syst. 2010, 39, 193-212. [CrossRef]

19. Benbunan-Fich, R.; Hiltz, S.R.; Turoff, M. A comparative content analysis of face-to-face vs. asynchronous group decision making. Decis. Support Syst. 2003, 34, 457-469. [CrossRef]

20. Callister, R.R.; Love, M.S. A Comparison of Learning Outcomes in Skills-Based Courses: Online Versus Face-To-Face Formats. Decis. Sci. J. Innov. Educ. 2016, 14, 243-256. [CrossRef]

21. Deschacht, N.; Goeman, K. The effect of blended learning on course persistence and performance of adult learners: A differencein-differences analysis. Comput. Educ. 2015, 87, 83-89. [CrossRef]

22. Wiechowski, L.S.; Washburn, T.L. Online Finance and Economics Courses: A Comparative Study of Course Satisfaction and Outcomes across Learning Models. Am. J. Bus. Educ. (AJBE) 2013, 7, 37-48. [CrossRef]

23. Bratianu, C.; Vatamanescu, E.-M. Students' perception on developing conceptual generic skills for business. VINE J. Inf. Knowl. Manag. Syst. 2017, 47, 490-505. [CrossRef]

24. Virtanen, A.; Tynjälä, P. Factors explaining the learning of generic skills: A study of university students' experiences. Teach. High. Educ. 2018, 24, 880-894. [CrossRef]

25. Bratianu, C.; Hadad, S.; Bejinaru, R. Paradigm Shift in Business Education: A Competence-Based Approach. Sustainability 2020, 12, 1348. [CrossRef]

26. Bruwer, J.-P.; Smith, J. The Role of Basic Business Skills Development and Their Influence on South African Small, Medium and Micro Enterprise Sustainability. J. Econ. Behav. Stud. 2018, 10, 48-62. [CrossRef]

27. Osadchiy, I.S.; Serezhkina, A.E. Project-based education as a cross-functional competences development approach. In Proceedings of the SPIE 11516, Optical Technologies for Telecommunications 2019, Kazan, Russia, 22 May 2020; Volume 11516, p. 115161Y.

28. Bratianu, C.; Bejinaru, R. The Theory of Knowledge Fields: A Thermodynamics Approach. Systems 2019, 7, 20. [CrossRef]

29. Bratianu, C.; Andriessen, D. Knowledge as Energy: A Metaphorical Analysis. J. Commun. Stud. 2008, 3, 75-82.

30. Bratianu, C.; Bejinaru, R. Knowledge dynamics: A thermodynamics approach. Kybernetes 2019, 49, 6-21. [CrossRef]

31. Bratianu, C. Changing paradigm for knowledge metaphors from dynamics to thermodynamics. Syst. Res. Behav. Sci. 2011, 28, 160-169. [CrossRef]

32. Brewer, P.D.; Brewer, K.L. Knowledge Management, Human Resource Management, and Higher Education: A Theoretical Model. J. Educ. Bus. 2010, 85, 330-335. [CrossRef]

33. Sokól, A.; Figurska, I. Creativity as one of the core competencies of studying knowledge workers. Entrep. Sustain. Issues 2017, 5, 23-35. [CrossRef]

34. Zhao, Y.; Breslow, L. Literature Review on Hybrid/Blended Learning; Metropolitan Education Research Consortium: Virginia, VA, USA, 2013.

35. Bower, M.; Dalgarno, B.; Kennedy, G.E.; Lee, M.J.; Kenney, J. Design and implementation factors in blended synchronous learning environments: Outcomes from a cross-case analysis. Comput. Educ. 2015, 86, 1-17. [CrossRef]

36. Bowyer, J.; Chambers, L.C. Evaluating Blended Learning: Bringing the Elements Together; Cambridge Assessment: Cambridge, UK, 2017; No. 23.

37. Dragicevic, N.; Pavlidou, I.; Tsui, E. Use of Hybrid Classroom and Open Educational Resources: Experience Gained from a Uni-versity in Hong Kong. In Proceedings of the 2020 International Conference e-Learning, 21-23 July 2020; Available online: http: / / www.wikicfp.com/cfp/servlet/event.showcfp?eventid=98013\&copyownerid=118738 (accessed on 30 March 2021).

38. Gallardo-Echenique, E.E.; de Oliveira, J.M.; Marqués-Molias, L.; Esteve-Mon, F. Digital Competence in the Knowledge Society. J. Online Learn. Teach. 2015, 11, 17.

39. Germaine, R.; Richards, J.; Koeller, M.; Schubert-Irastorza, C. Purposeful Use of 21st Century Skills in Higher Education. J. Res. Innov. Teach. 2016, 9.

40. Muller, A.; Hutchins, N.; Pinto, M.C. Applying open innovation where your company needs it most. Strat. Leadersh. 2012, 40, 35-42. [CrossRef]

41. Siemens, G. Learning and Knowing in Networks: Changing Roles for Educators and Designers. ITFORUM Discuss. 2008, 27, $1-26$. 
42. Hummel, K.; Pfaff, D.; Rost, K. Does Economics and Business Education Wash Away Moral Judgment Competence? J. Bus. Ethics 2018, 150, 559-577. [CrossRef]

43. Qi, J. The Founder's Notes; LID Publishing: Ciudad de Mexico, Mexico, 2020.

44. Kakihara, M.; Sørensen, C. Exploring Knowledge Emergence: From Chaos to Organizational Knowledge. J. Glob. Inf. Technol. Manag. 2002, 5, 48-66. [CrossRef]

45. Hansen, M.T. The Search-Transfer Problem: The Role of Weak Ties in Sharing Knowledge across Organization Subunits. Adm. Sci. Q. 1999, 44, 82. [CrossRef]

46. Kogut, B.; Zander, U. Knowledge of the Firm, Combinative Capabilities, and the Replication of Technology. Organ. Sci. 1992, 3 , 383-397. [CrossRef]

47. Roberts, C.W. A Conceptual Framework for Quantitative Text Analysis. Qual. Quant. 2000, 34, 259-274. [CrossRef]

48. Nonaka, I.; Takeuchi, H. The Knowledge Creating Company: How Japanese Companies Create the Dynamics of Innovation; Oxford University Press: Oxford, UK, 1995.

49. Zembylas, M. Emotional ecology: The intersection of emotional knowledge and pedagogical content knowledge in teaching. Teach. Teach. Educ. 2007, 23, 355-367. [CrossRef]

50. Butz, N.T.; Stupnisky, R.H.; Pekrun, R.; Jensen, J.L.; Harsell, D.M. The Impact of Emotions on Student Achievement in Synchronous Hybrid Business and Public Administration Programs: A Longitudinal Test of Control-Value Theory. Decis. Sci. J. Innov. Educ. 2016, 14, 441-474. [CrossRef]

51. Immordino-Yang, M.H.; Damasio, A. We Feel, Therefore We Learn: The Relevance of Affective and Social Neuroscience to Education. Mind Brain Educ. 2007, 1, 3-10. [CrossRef]

52. LaBar, K.S.; Cabeza, R. Cognitive neuroscience of emotional memory. Nat. Rev. Neurosci. 2006, 7, 54-64. [CrossRef] [PubMed]

53. Mayer, R.E. Searching for the role of emotions in e-learning. Learn. Instr. 2020, 70, 101213. [CrossRef]

54. Pekrun, R. Using Self-Report to Assess Emotions in Education. In Methodological Advances in Research on Emotion and Education; Springer International Publishing: New York, NY, USA, 2016; pp. 43-54.

55. Schukajlow, S.; Rakoczy, K.; Pekrun, R. Emotions and motivation in mathematics education: Theoretical considerations and empirical contributions. ZDM 2017, 49, 307-322. [CrossRef]

56. Zembylas, M.; Schutz, P.A. Introduction to Methodological Advances in Research on Emotion in Education. In Methodological Advances in Research on Emotion and Education; Springer International Publishing: New York, NY, USA, 2016 ; pp. 3-14.

57. Hanin, V.; Van Nieuwenhoven, C. Developing an Expert and Reflexive Approach to Problem-Solving: The Place of Emotional Knowledge and Skills. Psychology 2018, 9, 280-309. [CrossRef]

58. MacIntyre, P.D.; Vincze, L. Positive and negative emotions underlie motivation for L2 learning. Stud. Second. Lang. Learn. Teach. 2017, 7, 61-88. [CrossRef]

59. Bonesso, S.; Gerli, F.; Pizzi, C.; Cortellazzo, L. Students' Entrepreneurial Intentions: The Role of Prior Learning Experiences and Emotional, Social, and Cognitive Competencies. J. Small Bus. Manag. 2018, 56, 215-242. [CrossRef]

60. Ashar, H.; Lane-Maher, M. Success and Spirituality in the New Business Paradigm. J. Manag. Inq. 2004, 13, 249-260. [CrossRef]

61. Murray, B. The Purpose of Business: Why Values, Meaning and Purpose Really, Really Matter. Eff. Exec. 2019, $22,10-17$.

62. Tsui, E.; Dragicevic, N. Use of scenario development and personal learning environment and networks (PLE\&N) to support curriculum co-creation. Manag. Mark. 2018, 13, 848-858. [CrossRef]

63. Tsang, H.W.C.; Tsui, E. Conceptual design and empirical study of a personal learning environment and network (PLE\&N) to support peer-based social and lifelong learning. VINE J. Inf. Knowl. Manag. Syst. 2017, 47, 228-249. [CrossRef]

64. Taylor, M.C. Interviewing. In Qualitative Research in Health Care; Open University Press: New York, NY, USA, 2005 ; pp. $39-55$.

65. Castillo-Montoya, M. Preparing for Interview Research: The Interview Protocol Refinement Framework. TQR 2016, 21, 811-831.

66. Kallio, H.; Pietilä, A.-M.; Johnson, M.; Kangasniemi, M. Systematic methodological review: Developing a framework for a qualitative semi-structured interview guide. J. Adv. Nurs. 2016, 72, 2954-2965. [CrossRef]

67. Braun, V.; Clarke, V. Using thematic analysis in psychology. Qual. Res. Psychol. 2006, 3, 77-101. [CrossRef]

68. Braun, V.; Clarke, V. Thematic analysis. In APA Handbook of Research Methods in Psychology, Research Designs: Quantitative, Qualitative, Neuropsychological, and Biological; American Psychological Association (APA): Worcester, MA, USA, 2012; Volume 2, pp. $57-71$.

69. Boyatzis, R. Transforming Qualitative Information; SAGE Publishing: Thousand Oaks, CA, USA, 1998.

70. Tuckett, A.G. Applying thematic analysis theory to practice: A researcher's experience. Contemp. Nurse 2005, 19, 75-87. [CrossRef]

71. Szeto, E. A Comparison of Online/Face-to-face Students' and Instructor's Experiences: Examining Blended Synchronous Learning Effects. Procedia Soc. Behav. Sci. 2014, 116, 4250-4254. [CrossRef]

72. Jaggars, S.S. Choosing Between Online and Face-to-Face Courses: Community College Student Voices. Am. J. Distance Educ. 2014, 28, 27-38. [CrossRef]

73. Saghafi, M.; Franz, J.; Crowther, P. A Holistic Model for Blended Learning. J. Interact. Learn. Res. 2014, 25, 531-549.

74. Sit, J.W.; Chung, J.W.; Chow, M.C.; Wong, T.K. Experiences of online learning: Students' perspective. Nurse Educ. Today 2005, 25, 140-147. [CrossRef]

75. Savolainen, R. Approaching the Affective Factors of Information Seeking: The Viewpoint of the Information Search Process Model. Available online: http:/ / informationr.net/ir/20-1/isic2/isic28.html\#.YBZtImMRVMM (accessed on 31 January 2021). 
76. Rogers, P.C.; Graham, C.R.; Rasmussen, R.; Campbell, J.O.; Ure, D.M. Case 2: Blending Face-to-Face and Distance Learners in a Synchronous Class: Instructor and Learner Experiences. Q. Rev. Distance Educ. 2003, 4, 245-251.

77. Tambouris, E.; Zotou, M.; Tarabanis, K. Towards designing cognitively-enriched project-oriented courses within a blended problem-based learning context. Educ. Inf. Technol. 2012, 19, 61-86. [CrossRef]

78. Willems, J.; Bossu, C. Equity considerations for open educational resources in the glocalization of education. Distance Educ. 2012, 33, 185-199. [CrossRef]

79. Atenas, J.; Havemann, L.; Priego, E. Open Data as Open Educational Resources: Towards Transversal Skills and Global Citizenship. Open Praxis 2015, 7, 377-389. [CrossRef]

80. Natale, S.M.; Libertella, A.F. Online Education: Values Dilemma in Business and the Search for Empathic Engagement. J. Bus. Ethic. 2015, 138, 175-184. [CrossRef]

81. Boelens, R.; De Wever, B.; Voet, M. Four key challenges to the design of blended learning: A systematic literature review. Educ. Res. Rev. 2017, 22, 1-18. [CrossRef]

82. Wang, Y.D. Building student trust in online learning environments. Distance Educ. 2014, 35, 345-359. [CrossRef]

83. Internationalization-at-Home-SYA Project. Available online: https://www.polyu.edu.hk/syaproject/en/activity/polyu/iah/ (accessed on 31 January 2021).

84. Ora, A.; Sahatcija, R.; Ferhataj, A. Learning Styles and the Hybrid Learning: An Empirical Study about the Impact of Learning Styles on the Perception of the Hybrid Learning. Mediterr. J. Soc. Sci. 2018, 9, 137-148. [CrossRef]

85. Chen, B.H.; Chiou, H.-H. Learning style, sense of community and learning effectiveness in hybrid learning environment. Interact. Learn. Environ. 2012, 22, 485-496. [CrossRef] 